\title{
COMPORTAMENTO DE CULTIVARES DE CAFEEIRO \\ EM DIFERENTES DENSIDADES DE PLANTIO ${ }^{(1)}$
}

\author{
EDISON MARTINS PAULO ${ }^{(2)}$; ENES FURLANI JUNIOR ${ }^{(3)}$; LUIZ CARLOS FAZUOLI ${ }^{(4)}$
}

\begin{abstract}
RESUMO
Avaliou-se em Adamantina, na Região da Alta Paulista, em São Paulo, entre maio de 1995 e junho de 2000, o crescimento e quatro produções de cafeeiros das cultivares de porte baixo Catuaí Amarelo IAC 47 e Obatã IAC 1669-20 de Coffea arabica L., submetidas às densidades de plantio de 2.500, 5.000, 7.519 e 10.000 plantas ha ${ }^{-1}$, com uma planta por cova. Estudou-se também a população de 2.500 plantas.ha ${ }^{-1}$ em covas com duas plantas com 2,0 m de distância na linha de plantio. Adotou-se o delineamento estatístico de blocos ao acaso com três repetições, com parcelas subdivididas, onde as parcelas foram as populações e as subparcelas, as cultivares. Os resultados permitiram inferir que, no período estudado, o aumento da densidade influenciou positivamente a altura e negativamente o diâmetro do caule e da base da copa dos cafeeiros, mas não a altura da inserção do primeiro ramo plagiotrópico a partir do nível do solo. O aumento da população de cafeeiros acarretou menor produção de café beneficiado por planta, mas concorreu para o aumento da produtividade no período de 1997 a 2000. O plantio de duas mudas de café por cova acarretou também diminuição do diâmetro do caule e da produção individual dos cafeeiros. Observou-se na cultivar Catuaí Amarelo IAC 47 maior diâmetro da base da copa e maior crescimento em altura, enquanto a cv. Obatã IAC 1669-20 evidenciou seu maior diâmetro do caule. As cultivares Catuaí Amarelo IAC 47 e Obatã IAC 1669-20 não diferiram entre si quanto à produção individual e à produtividade de café beneficiado no quadriênio (1997-2000).
\end{abstract}

Palavras-chave: café, Coffea arabica L., densidade de plantas, competição.

\section{ABSTRACT}

\section{THE BEHAVIOR OF COFFEE CULTIVARS UNDER DIFFERENT PLANT DENSITIES}

This experiment was developed at Adamantina, west region of the State of São Paulo, Brazil, during May of 1995 to June of 2000. The plant growth and productivity of two coffee cultivars Catuaí Amarelo IAC 47 and Obatã IAC 1669-20, were evaluated considering to plant densities of 2.500, 5.000, 7.519 and 10.000 plants ha ${ }^{-1}$. The density of 2500 also was studied with two plants in the same hole, spaced of 2,0 $\mathrm{m}$ in the plant line. The experimental design was the randomized completely blocks with three replications, using the split-plot system. The plots were the densities and the split-plots were the cultivars. Results showed that, with increasing of the planting density, the plant height also increased, while the stem and plant basis diameters were reduced, however the planting density did not affect the height of

(1) Apresentado pelo primeiro autor como parte das exigências para a obtenção do título de Mestre em Agronomia no Programa de Pós-graduação da Faculdade de Engenharia de Ilha Solteira (FEIS) - UNESP. Recebido para publicação em 22 de outubro de 2004 e aceito em 21 de junho de 2005.

${ }^{(2)}$ Pólo Regional de Desenvolvimento Tecnológico dos Agronegócios da Alta Paulista/DDD/APTA/SAA-SP, Caixa Postal 191, 17800-000 Adamantina (SP). E-mail: poloaltapaulista@aptaregional.sp.gov.br Pós-graduando em Agronomia, Área de Sistema de Produção, FEIS - UNESP.

$\left(^{3}\right)$ FEIS/UNESP - Campus de Ilha Solteira, Caixa Postal 31, 15385-000 Ilha Solteira (SP).

$\left({ }^{4}\right)$ Centro de Café 'Alcides Carvalho', IAC/APTA/SAA-SP. 
the first branch. The increase of the planting density also increased the field productivity and reduced the production of individual plant. The cultivation of two plants at the same hole reduced the stem diameter and the plant yield. The cultivar Catuaí Amarelo IAC 47 showed the higher plant height and the higher plant basis diameter while cv. Obatã IAC 1669-20 showed the higher stem diameter. The field productivity and individual plant productivity were not different between those cultivars in the period studied (1997-2000).

Key-words: coffee, Coffea arabica L., density of the plants, competition.

\section{INTRODUÇÃO}

A produtividade da lavoura de café depende principalmente da cultivar e da densidade de plantio adotadas no estabelecimento da cultura. Podem ocorrer diferenças na produtividade quando cultivares de cafeeiros vegetam no mesmo ambiente e ao mesmo tempo (SiqueIRA et al., 1983). Aumentos na produtividade de cafeeiros de porte baixo têm sido obtidos com o aumento da população até 10.000 plantas por hectare (Valencia, 1973; Uribe e Mestre, 1988a,b, PAVAN et al. 1994).

A cultura do café possui inúmeras possibilidades de disposição de uma mesma população de plantas no campo, combinando-se os muitos espaçamentos possíveis entre as linhas da cultura, com as distâncias entre as covas nas linhas de plantio e com o número de plantas em cada cova. $\mathrm{Na}$ maioria dos países cafeicultores, atualmente, planta-se um cafeeiro por cova, mas, em alguns países, adota-se também o sistema com mais de uma planta devido a fatores estabilizadores da colheita, melhoria da produção e diminuição do replantio (URIBE e Mestre, 1988b). A resposta da produtividade da lavoura cafeeira à distância entre covas é linear, correspondendo à maior distância de plantio, menor produção por área quando se emprega uma planta por cova (Uribe e Mestre, 1988a). Usando-se o mesmo número de plantas por área, cafeeiros de porte baixo e com covas distanciadas de 1,0 $\mathrm{m}$ na linha de plantio e com uma planta têm, na média de diferentes espaçamentos, maior produtividade que aqueles espaçados por 2,0 m e com duas plantas (CAMARGO et al., 1985), o que parece não ocorrer quando se emprega o espaçamento de $4,0 \mathrm{~m}$ entre as linhas da cultura (SiqueIra et al., 1983).

Na definição do espaçamento entre as linhas de plantio tem sido proposto considerar o diâmetro da copa do cafeeiro adulto e o espaço livre desejado pelo produtor para o manejo da lavoura (ANDROCIOLI Filho, 1994). Tem-se verificado que o aumento na população de plantas em cultivares de porte baixo causa diminuição do diâmetro da saia e do caule dos cafeeiros e aumento da altura das plantas (NJOROJE et al., 1992, ReNA et al., 1996).
O presente trabalho relata os estudos do crescimento e da produção das cultivares de cafeeiro arábica de porte baixo Catuaí Amarelo IAC 47 e Obatã IAC 1669-20 submetidas a quatro densidades de plantio em Adamantina, Região da Alta Paulista, em São Paulo, buscando obter informações para o melhor estabelecimento das lavouras de café .

\section{MATERIAL E MÉTODOS}

O experimento foi instalado em maio de 1995, em área do Pólo Regional de Desenvolvimento Tecnológicos dos Agronegócios da Alta Paulista, localizado no município de Adamantina, Região da Nova Alta Paulista, São Paulo, latitude $21^{\circ} 42^{\prime} \mathrm{S}$ e longitude $51^{\circ} 08^{\prime} \mathrm{W}$, com altitude de $453 \mathrm{~m}$ (CAVICHIOLI, 1998), em Latossolo Vermelho-Escuro, eutrófico A moderado, textura média (PRADO et al., 2003) e clima Cwa, segundo a classificação de Köeppen (Mello et al., 1994).

Adotou-se o delineamento estatístico de blocos ao acaso com três repetições, esquema fatorial com parcelas subdivididas, cujos fatores foram populações e cultivares de cafeeiro (Coffea arábica L.) que, respectivamente, constituíram as parcelas e as subparcelas. As populações de 2.500, 5.000, 7.519 e 10.000 plantas por hectare foram estabelecidas em linhas de cafeeiros espaçadas respectivamente por 4,0 , $2,0,1,33$ e $1,0 \mathrm{~m}$ e em covas distanciadas por $1,0 \mathrm{~m}$ entre si, com uma planta em cada uma. Estudou-se um tratamento adicional na população com 2.500 plantas por hectare, cujas covas, nas linhas de plantio, foram distanciadas por 2,0 $\mathrm{m}$ e receberam duas mudas de cafeeiros. As cultivares de porte baixo estudadas foram a Catuaí Amarelo IAC 47 e a Obatã IAC 1669-20 (FAZUOLI, 1995; FAZUOLI et al. 2002).

As subparcelas apresentavam bordadura e área útil variando de $32 \mathrm{~m}^{2}$ para a população de 1.250 covas por hectare com duas plantas em cada uma, até $55 \mathrm{~m}^{2}$ para a população de 10.000 plantas por hectare.

As covas para o plantio foram feitas manualmente com o uso de cavadeira e com as dimensões de $0,40 \times 0,40 \mathrm{~m}$ e com $0,50 \mathrm{~m}$ de profundidade e receberam a adubação de $27 \mathrm{~g}$ de $\mathrm{P}_{2} \mathrm{O}_{5}$, 
$11,6 \mathrm{~g}$ de $\mathrm{K}_{2} \mathrm{O}$ por cova e $50 \mathrm{~g}$ de calcário. Após o pegamento das mudas, no período de setembro de 1995 a março de 1996, aplicou-se em cobertura $16 \mathrm{~g}$ de $\mathrm{N}$ por cova. As adubações minerais de formação e de produção foram realizadas, seguindo as recomendações de RAIJ et al. (1997), no período de outubro a abril.

Realizou-se o controle de pragas e doenças, usando-se ingredientes ativos recomendados para a cultura e aplicados igualmente em todos os tratamentos.

No período experimental, avaliou-se a produção de café, a altura das plantas e da inserção do primeiro par de ramos a partir do solo, o diâmetro da copa e o diâmetro do caule das plantas de cada um dos tratamentos. A altura das plantas foi medida com uma régua topográfica colocada paralelamente ao caule do cafeeiro e limitando-o transversalmente com uma haste no topo do dossel. Em 2000, obteve-se a altura do primeiro ramo dos cafeeiros a partir do nível do solo com uma fita métrica. Efetuaram-se as leituras do diâmetro da base da copa, estendendo-se uma fita métrica da base até o ponto de inserção do primeiro par de folhas presentes no ápice de cada unidade do primeiro par de ramos opostos dos cafeeiros. O diâmetro do caule foi obtido nos anos 1999 e 2000 com o auxílio de um paquímetro na altura de $0,40 \mathrm{~m}$ do solo.
As colheitas foram efetuadas no período de março a agosto e os dados biométricos obtidos em outubro de 1996, fevereiro de 1997 e de 1998, junho de 1999 e janeiro de 2000 em quatro plantas marcadas e escolhidas ao acaso na área útil das parcelas. A primeira das colheitas realizou-se em 14 de abril de 1997 e a última em 20 de junho de 2000.

Obteve-se a produção de café colhendo-se os frutos das plantas das áreas úteis das parcelas em estádios de desenvolvimento, desde verde-amarelado até passa, estando a grande maioria no estádio de cereja. Anualmente, no momento da primeira colheita de cada subparcela, coletou-se uma amostra de 3,0 kg de frutos que foi seca e beneficiada e a partir da qual calculou-se o rendimento que foi utilizado como base para o cálculo de café beneficiado por tratamento.

Os dados foram submetidos à análise da variância, aplicando-se o teste F para a verificação de diferenças significativas entre as densidades de plantio, as cultivares e os contrastes ortogonais dos tratamentos com 2.500 plantas por hectare (Tabela 1) e, para as variáveis com F significativo, realizou-se o estudo de regressão para as densidades de plantio e utilizou-se o teste de Tukey para a comparação das médias das cultivares, conforme os procedimentos descritos em Gomes (1978) e utilizando-se o programa estatístico SAS.

Tabela 1. Esquema da análise da variância aplicada aos dados das variáveis estudadas no experimento

\begin{tabular}{|c|c|c|c|c|}
\hline F.V. & G.L. & & E (Q.M.) & $\mathrm{F}$ \\
\hline População (P) & $(\mathrm{I}-1)$ & (F) & $\mathrm{N}^{2}+\mathrm{J}_{1}+\mathrm{N}_{\mathrm{i}}^{2} \mathrm{tb}+\mathrm{J}_{2} \Sigma \mathrm{t}^{2}{ }_{\mathrm{i}}$ & $\mathrm{QM}(\mathrm{P}) / \mathrm{QMR}(\mathrm{A})$ \\
\hline $\begin{array}{l}\text { Contraste }(\mathrm{Cp}) \\
(4 \times 2 \times 2) \text { vs }(4 \times 1 \times 1)\end{array}$ & $(\mathrm{N}-1)$ & & & $\mathrm{QM}(\mathrm{Cp}) / \mathrm{QMR}(\mathrm{A})$ \\
\hline Blocos & $(\mathrm{J}-1)$ & (A) & & \\
\hline Resíduo (A) & $(\mathrm{I}-1)(\mathrm{J}-1)$ & (A) & $\Sigma^{2}+\mathrm{J}_{1}+\mathrm{N}_{\mathrm{tb}}^{2}$ & \\
\hline Parcelas & $(\mathrm{I} \mathrm{J}-1)$ & & & \\
\hline Cultivar (C) & $(\mathrm{K}-1)$ & (F) & $\mathrm{N}^{2}+\mathrm{J}_{\mathrm{k}} \Sigma \mathrm{t}^{\prime 2}{ }_{\mathrm{k}}$ & $\mathrm{QM}(\mathrm{C}) / \mathrm{QMR}(\mathrm{B})$ \\
\hline $\begin{array}{l}\text { Contraste }(\mathrm{Cc}) \\
\text { (Porte alto) vs (Porte baixo) }\end{array}$ & $(\mathrm{N}-1)$ & & & $\mathrm{QM}(\mathrm{Cc}) / \mathrm{QMR}(\mathrm{B})$ \\
\hline $\mathrm{P} \times \mathrm{C}$ & $(\mathrm{I}-1)(\mathrm{K}-1)$ & (F) & $\mathrm{N}^{2}+\underset{\mathrm{I}, \mathrm{K}}{\mathrm{J}_{4} \sum}\left(\mathrm{t} \mathrm{t}_{\mathrm{i}, \mathrm{k}}\right)^{2}$ & $\mathrm{QM}(\mathrm{PxC}) / \mathrm{QMR}(\mathrm{B})$ \\
\hline Resíduo (B) & $\mathrm{I}(\mathrm{J}-1)(\mathrm{K}-1)$ & (A) & $\mathrm{N}^{2}$ & \\
\hline Total & $(\mathrm{IKJ}-1)$ & & & \\
\hline
\end{tabular}

F.V. = Fonte de variação. G.L. = Grau de Liberdade. E (Q.M.) = Esperança dos quadrados médios. 


\section{RESULTADOS E DISCUSSÃO}

\subsection{Altura das plantas}

O aumento da população de cafeeiros resultou em significativo $(p<0,01)$ crescimento das plantas em altura nos três últimos anos da experimentação (Tabela 2) (Figura1). A cultivar Catuaí Amarelo IAC 47 sempre foi mais alta que a Obatã IAC 1669-20, porém somente em 1999 e 2000 foram significativas $(p<0,01)$ as diferenças observadas entre elas. A interação entre os fatores população e cultivar, bem como o contraste entre as alturas das populações de 2.500 plantas ha $^{-1}$, estabelecidas com uma e duas plantas por cova, não foi significativo $(p>0,01)$. $O$ estudo de regressão da altura da população, média das cultivares, mostrou significância a níveis lineares em $1998(\mathrm{p}<0,01)$ e $2000(\mathrm{p}<0,01)$ e até o $4 .^{\circ}$ grau $(p<0,05)$ em 1999. Os resultados obtidos para a altura de plantas confirmam de modo geral o de outros autores, tanto para o número de plantas por cova (Almeida e Matiello, 1980), quanto para o aumento da população de cafeeiros em cultivares de porte baixo (NJOROJe et al., 1992, ReNA et al., 1996). É fato conhecido que a altura do cafeeiro aumenta com a idade e com decréscimo do espaçamento, sem tendência visível de estabilização, tendendo o aumento da iluminação, a ser obtido em espaçamentos mais abertos, produzir plantas mais baixas e diferenciadas (RENA et al., 1998), o que é confirmado pelos resultados obtidos (Tabela 2; Figura 1). As diferenças observadas, bem como a menor taxa de crescimento verificada entre 1999 e 2000, comparativamente aos anos anteriores (Figura 1; Tabela 2), possivelmente estão relacionadas à prolongada estiagem ocorrida no período (Tabela 3).

Tabela 2. Altura dos cafeeiros Catuaí Amarelo IAC 47 e Obatã IAC 1669-20 submetidos a diferentes densidades de plantio. Os dados são médias de três repetições

\begin{tabular}{|c|c|c|c|c|}
\hline Tratamento & 1997 & 1998 & 1999 & 2000 \\
\hline \multicolumn{5}{|l|}{ População (P) } \\
\hline \multicolumn{5}{|l|}{ Plantas.ha ${ }^{-1}$} \\
\hline $2.500^{(1)}$ & 96,58 & 131,88 & 154,88 & 162,75 \\
\hline $2.500^{(2)}$ & 98,79 & 132,49 & 153,05 & 157,67 \\
\hline 5.000 & 95,62 & 136,58 & 164,60 & 168,92 \\
\hline 7.519 & 101,27 & 137,32 & 166,99 & 173,53 \\
\hline 10.000 & 103,17 & 139,41 & 176,22 & 181,63 \\
\hline \multicolumn{5}{|l|}{ Cultivar (C) } \\
\hline Catuaí & 101,89 & 138,27 & 169,78 a & $176,40 \mathrm{a}$ \\
\hline Obatã & 96,28 & 132,80 & $156,51 \mathrm{~b}$ & $161,40 \mathrm{~b}$ \\
\hline $\mathrm{F}(\mathrm{P})$ & $1,99 \mathrm{~ns}$ & $7,61 * *$ & $41,64 * *$ & 15,30 ** \\
\hline $\mathrm{F}(1,2)$ & $0,20 \mathrm{~ns}$ & $0,02 \mathrm{~ns}$ & $0,19 \mathrm{~ns}$ & $1,45 \mathrm{~ns}$ \\
\hline $\mathrm{F}(\mathrm{C}$ & $3,16 \mathrm{~ns}$ & $3,40 \mathrm{~ns}$ & $25,52 * *$ & $31,53 * *$ \\
\hline$F(P) \times(C)$ & $0,61 \mathrm{~ns}$ & $0,53 \mathrm{~ns}$ & $0,98 \mathrm{~ns}$ & $1,42 \mathrm{~ns}$ \\
\hline F RL & - & $28,71 * *$ & $149,12 * *$ & 50,65 ** \\
\hline F RQ & - & $0,01 \mathrm{~ns}$ & $5,57 *$ & $4,90 \mathrm{~ns}$ \\
\hline $\mathrm{F} 3^{\circ} \mathrm{G}$ & - & $0,33 \mathrm{~ns}$ & $1,98 \mathrm{~ns}$ & $2,90 \mathrm{~ns}$ \\
\hline $\mathrm{F} 4^{\circ} \mathrm{G}$ & - & $1,38 \mathrm{~ns}$ & $9,87 *$ & $2,76 \mathrm{~ns}$ \\
\hline C.V.(P) (\%) & 5,53 & 2,12 & 2,20 & 3,46 \\
\hline C.V.(C) (\%) & 8,71 & 5,99 & 4,41 & 4,33 \\
\hline
\end{tabular}

( ${ }^{1}$ População de 2.500 plantas.ha ${ }^{-1}$ no espaçamento $4 \times 2 \mathrm{~m}$ com duas plantas por cova.

$\left({ }^{2}\right)$ População de 2.500 plantas.ha ${ }^{-1}$ no espaçamento $4 \times 1 \mathrm{~m}$ com uma planta por cova.

$\mathrm{F}^{(1,2)}=$ Valor de $\mathrm{F}$ do contraste entre os tratamentos $4 \times 2 \times 2$ e $4 \times 1 \times 1$.

$\mathrm{RL}=$ Regressão linear. $\mathrm{RQ}=$ Regressão quadrática. $\mathrm{R} 3 \mathrm{G}=$ Regressão de $3 .^{\circ}$ grau. $\mathrm{R} 4 \mathrm{G}=$ Regressão de $4 .{ }^{\circ}$ grau

$\mathrm{ns}=$ não significativo. 


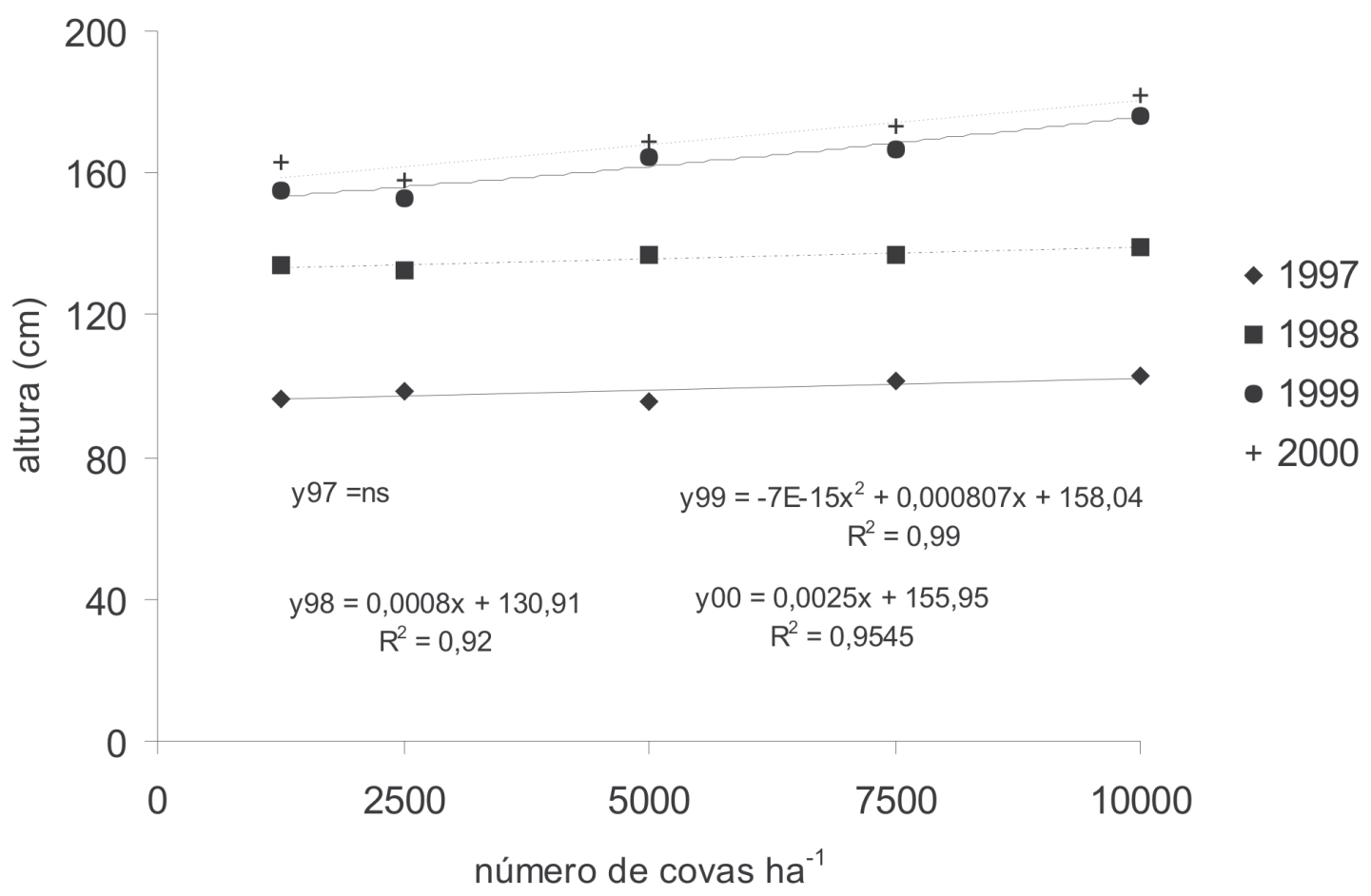

Figura 1. Altura média de cafeeiros de porte baixo submetidos a diferentes densidades de plantio.

Tabela 3. Temperatura média (Tmed), precipitação pluvial (Prec) e balanço hídrico (BH) mensal do local da experimentação no ano agrícola de 1999-2000

\begin{tabular}{|c|c|c|c|c|c|c|c|c|c|c|c|c|}
\hline Mês & Set & Out & Nov & Dez & Jan & Fev & Mar & Abr & Mai & Jun & Jul & Ago \\
\hline & \multicolumn{4}{|c|}{1999} & \multicolumn{8}{|c|}{2000} \\
\hline Tmed $\left({ }^{\circ} \mathrm{C}\right)$ & 24,0 & 25,2 & 24,7 & 26,8 & 27,2 & 26,4 & 25,8 & 24,1 & 21,1 & 22,4 & 17,6 & 22,3 \\
\hline Prec $(\mathrm{mm})$ & 36 & 12 & 50 & 244 & 90 & 196 & 277 & 34 & 24 & 14 & 41 & 71 \\
\hline $\mathrm{BH} \quad(\mathrm{mm})$ & -58 & -109 & -70 & 0 & -27 & 6 & 146 & -18 & -27 & -48 & 0 & -8 \\
\hline
\end{tabular}

\subsection{Diâmetro do caule}

O diâmetro do caule das cultivares tendeu a diminuir com o aumento da densidade de plantio, verificando-se diferenças significativas $(p<0,05)$ entre as populações de plantas em 1999, mas não em 2000 (Tabela 4). Nesse ano, a cv. Catuaí Amarelo IAC 47 com diâmetro do caule significativamente $(p<0,05)$ maior que a cv. Obatã IAC 1669-20 e o diâmetro médio do caule da população de 2.500 plantas.ha ${ }^{-1}$ estabelecida com uma planta por cova foi significativamente maior que aquela com duas plantas por cova $(p<0,01)$. A interação entre os fatores população e cultivar não foi significativa $(p>0,05)$ para a variável diâmetro do caule (Tabela 4). Observou-se no estudo de regressão do diâmetro do caule da planta para população com a média das cultivares significância em nível quadrático $(p<0,05)$ em 1999 (Figura 2).

As respostas obtidas para o diâmetro do caule relacionado ao aumento da população concordam com o relatado por outros autores para cafeeiros de porte baixo (NJoroje et al., 1992, RENA et al., 1994). No entanto, na cultivar Catuaí Vermelho, também de porte baixo, plantada no espaçamento 4,0 x 1,5 m não foram observadas diferenças de diâmetro do caule entre as plantas estabelecidas em covas com uma e duas mudas (Almeida e Matiello, 1980). 
Tabela 4. Diâmetro do caule dos cafeeiros Catuaí Amarelo IAC 47 e Obatã IAC 1669-20 submetidos a diferentes densidades de plantio. Os dados são médias de três repetições

\begin{tabular}{|c|c|c|}
\hline Tratamento & 1999 & 2000 \\
\hline \multicolumn{3}{|l|}{ População (P) } \\
\hline \multicolumn{3}{|l|}{ Plantas ha ${ }^{-1}$} \\
\hline $2.500^{(1)}$ & 46,92 & 47,17 \\
\hline $2.500^{(2)}$ & 50,32 & 52,36 \\
\hline 5.000 & 47,50 & 49,15 \\
\hline 7.519 & 46,00 & 45,74 \\
\hline 10.000 & 43,61 & 44,71 \\
\hline \multicolumn{3}{|l|}{ Cultivar (C) } \\
\hline Catuaí & 45,63 & 46,63 \\
\hline Obatã & 48,11 & 49,02 \\
\hline $\mathrm{F}(\mathrm{P})$ & $5,56^{*}$ & $2,92 \mathrm{~ns}$ \\
\hline$F(1,2)$ & $2,95 \mathrm{~ns}$ & $11,21 * *$ \\
\hline $\mathrm{F}(\mathrm{C})$ & $3,92 \mathrm{~ns}$ & $5,93 *$ \\
\hline $\mathrm{F}(\mathrm{P}) \times(\mathrm{C})$ & $0,81 \mathrm{~ns}$ & $1,59 \mathrm{~ns}$ \\
\hline F RL & $11,21 *$ & - \\
\hline F RQ & 7,07 * & - \\
\hline $\mathrm{F} 3 .^{\circ} \mathrm{G}$ & $2,67 \mathrm{~ns}$ & - \\
\hline $\mathrm{F} 4 .^{\circ} \mathrm{G}$ & $1,28 \mathrm{~ns}$ & - \\
\hline CV (P) (\%) & 5,39 & 9,09 \\
\hline CV $(\mathrm{C})(\%)$ & 7,33 & 5,61 \\
\hline
\end{tabular}

(1) População de 2.500 plantas.ha ${ }^{-1}$ no espaçamento $4 \times 2 \mathrm{~m}$ com duas plantas por cova.

$\left(^{2}\right)$ População de 2.500 plantas.ha ${ }^{-1}$ no espaçamento $4 \times 1 \mathrm{~m}$ com uma planta por cova.

$\mathrm{F}^{(1,2)}=$ Valor de $\mathrm{F}$ do contraste entre os tratamentos $4 \times 2 \times 2$ e $4 \times 1 \times 1$.

$\mathrm{RL}=$ Regressão linear. $\mathrm{RQ}=$ Regressão quadrática. $\mathrm{R} 3 \mathrm{G}=$ Regressão de $3 .^{\circ}$ grau. $\mathrm{R} 4 \mathrm{G}=$ Regressão de $4 .^{\circ}$ grau. ns = não significativo.

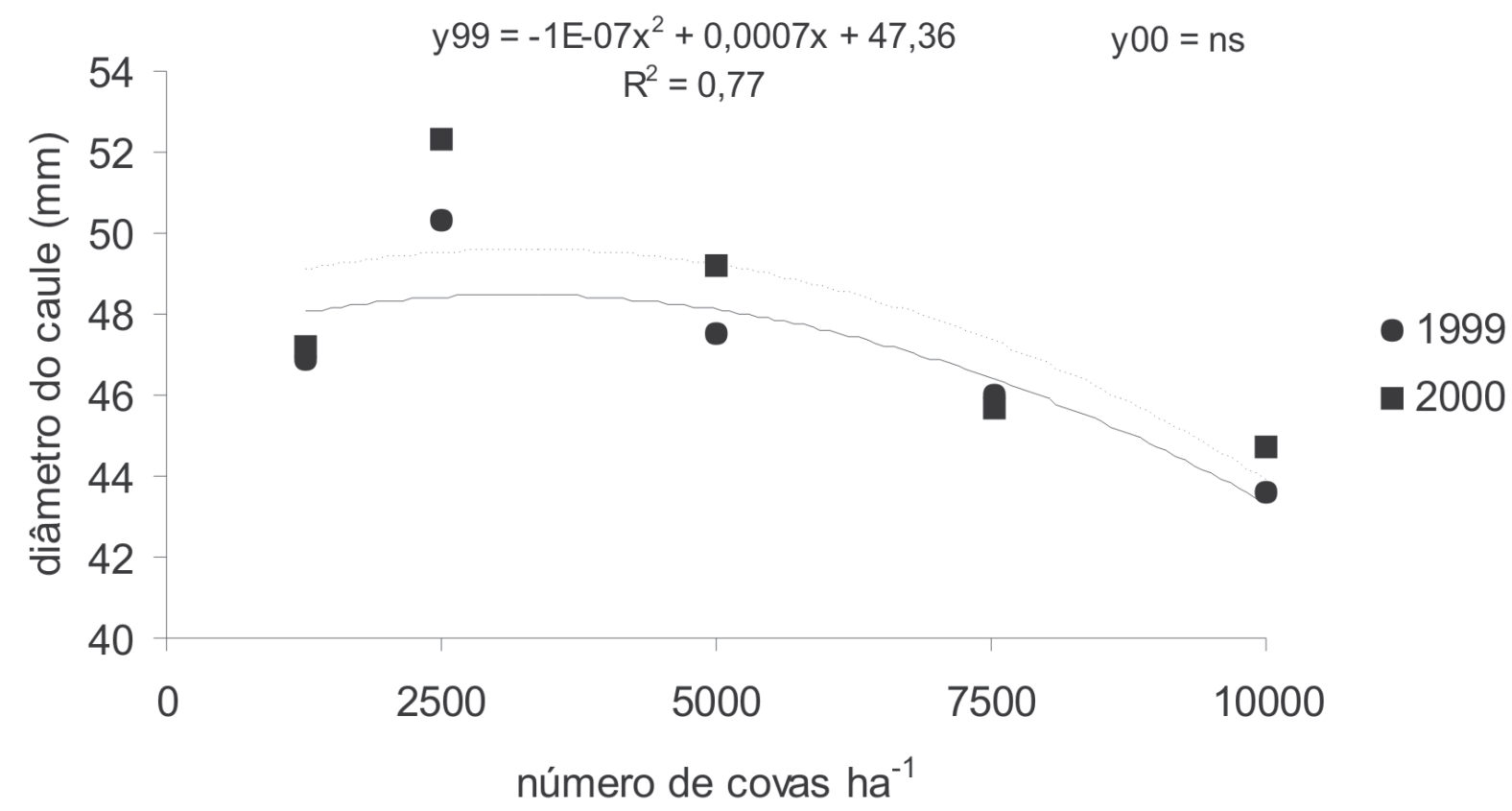

Figura 2. Diâmetro médio do caule de cafeeiros de porte baixo submetidos a diferentes densidades de plantio. 


\subsection{Diâmetro da base da copa}

O diâmetro da base da copa diminuiu com o aumento da população de cafeeiros, sendo significativas $(p<0,01)$ as diferenças observadas entre as populações em 1999 e 2000 (Tabela 5). O contraste realizado entre os tratamentos com 2.500 plantas ha ${ }^{1}$ revelou diferenças significativas $(p<0,05)$ entre o diâmetro da copa das populações em 1998 e 1999. Em 1998, na população de 2.500 plantas $\mathrm{ha}^{-1}$, estabelecida com uma planta por cova, observou-se maior diâmetro da base da copa que aquela com duas plantas por cova, ocorrendo o contrário em 1999. As cultivares diferiram significativamente $(p<0,05)$ quanto ao diâmetro da copa em 1998 e 2000 e, em 1998, o maior tamanho coube a cv.Obatã IAC 1669-20 e em 2000 à cv. Catuaí Amarelo IAC 47.

A interação entre os fatores população e cultivar somente foi significativa $(p<0,01)$ em 1998, cujo desdobramento mostrou que o diâmetro do caule diminui significativamente $(p<0,01)$ segundo modelo quadrático para a cv. Obatã IAC 1669-20 e em nível de terceiro grau para a cv. Catuaí Amarelo IAC 47 com o aumento da população de cafeeiros.

Merece ser mencionado que, após 1998, as duas cultivares, notoriamente nas populações a partir de 2.500 plantas ha ${ }^{-1}$ estabelecidas com uma planta por cova, diminuíram o diâmetro da base da copa com o tempo (Tabela 5; Figura 3), o que pode estar relacionado à perda de pares das folhas da extremidade dos ramos plagiotrópicos. Nos climas tropicais, a abscisão foliar tem sido associada com a precipitação pluvial e a duração do dia, sendo intensificada em períodos de seca (RENA e MAEstri, 1986) uma vez que, sem dúvida, a queda de folhas no cafeeiro é uma maneira de conservar água (RENA e MAestri, 1987). Deve ser ressaltado que as medições do diâmetro da base da copa em 1999 e 2000 foram realizadas em junho, época caracterizada por intensa deficiência hídrica (Tabela 3).

Tabela 5. Diâmetro da base da copa dos cafeeiros Catuaí Amarelo IAC 47 e Obatã IAC 1669-20 submetidas a diferentes densidades de plantio. Os dados são médias de três repetições

\begin{tabular}{|c|c|c|c|c|}
\hline Tratamento & 1997 & 1998 & 1999 & 2000 \\
\hline \multicolumn{5}{|l|}{ Po-pulação (P) } \\
\hline \multicolumn{5}{|l|}{ Plantas ha ${ }^{-1}$} \\
\hline $2.500^{(1)}$ & 58,96 & 152,92 & 149,04 & 150,33 \\
\hline $2.500^{(2)}$ & 62,15 & 158,07 & 137,23 & 142,84 \\
\hline 5.000 & 59,02 & 149,25 & 138,23 & 130,68 \\
\hline 7.519 & 60,96 & 139,60 & 124,83 & 110,66 \\
\hline 10.000 & 56,41 & 134,95 & 109,10 & 93,80 \\
\hline \multicolumn{5}{|l|}{ Cultivar (C) } \\
\hline Catuaí & 57,42 & 145,47 & 132,59 & 132,08 \\
\hline Obatã & 61,57 & 148,44 & 130,82 & 119,24 \\
\hline $\mathrm{F}(\mathrm{P})$ & $1,34 \mathrm{~ns}$ & $3,73 \mathrm{~ns}$ & $18,70 * *$ & $12,61 * *$ \\
\hline $\mathrm{F}\left({ }^{1,2}\right)$ & $1,14 \mathrm{~ns}$ & $6,76 *$ & $8,08 *$ & $1,31 \mathrm{~ns}$ \\
\hline $\mathrm{F}(\mathrm{C})$ & $4,82 \mathrm{~ns}$ & $5,59 *$ & $0,46 \mathrm{~ns}$ & $9,59 *$ \\
\hline$F(P) \times(C)$ & $0,54 \mathrm{~ns}$ & $9,62 * *$ & $1,63 \mathrm{~ns}$ & $1,86 \mathrm{~ns}$ \\
\hline F RL & - & - & $68,28 * *$ & $49,04 * *$ \\
\hline F RQ & - & - & $2,87 \mathrm{~ns}$ & $1,18 \mathrm{~ns}$ \\
\hline $\mathrm{F} 3 .^{\circ} \mathrm{G}$ & - & - & $1,84 \mathrm{~ns}$ & $0,14 \mathrm{~ns}$ \\
\hline $\mathrm{F} 4 .^{\circ} \mathrm{G}$ & - & - & $1,82 \mathrm{~ns}$ & $0,07 \mathrm{~ns}$ \\
\hline C.V. (P) (\%) & 7,79 & 8,22 & 6,57 & 12,78 \\
\hline C.V.(C) (\%) & 8,72 & 2,34 & 5,47 & 9,04 \\
\hline
\end{tabular}

( $\left.{ }^{1}\right)$ População de 2.500 plantas.ha ${ }^{-1}$ no espaçamento $4 \times 2 \mathrm{~m}$ com duas plantas por cova.

$\left(^{2}\right)$ População de 2.500 plantas.ha ${ }^{-1}$ no espaçamento $4 \times 1 \mathrm{~m}$ com uma planta por cova.

$\mathrm{F}^{(1,2)}$ Valor de $\mathrm{F}$ do contraste entre os tratamentos $4 \times 2 \times 2$ e $4 \times 1 \times 1$.

$\mathrm{RL}=$ Regressão linear. $\mathrm{RQ}=$ Regressão quadrática. $\mathrm{R} 3 \mathrm{G}=$ Regressão de $3 .^{\circ}$ grau. $\mathrm{R} 4 \mathrm{G}=$ Regressão de $4 .{ }^{\circ}$ grau. $\mathrm{ns}=$ não significativo. 


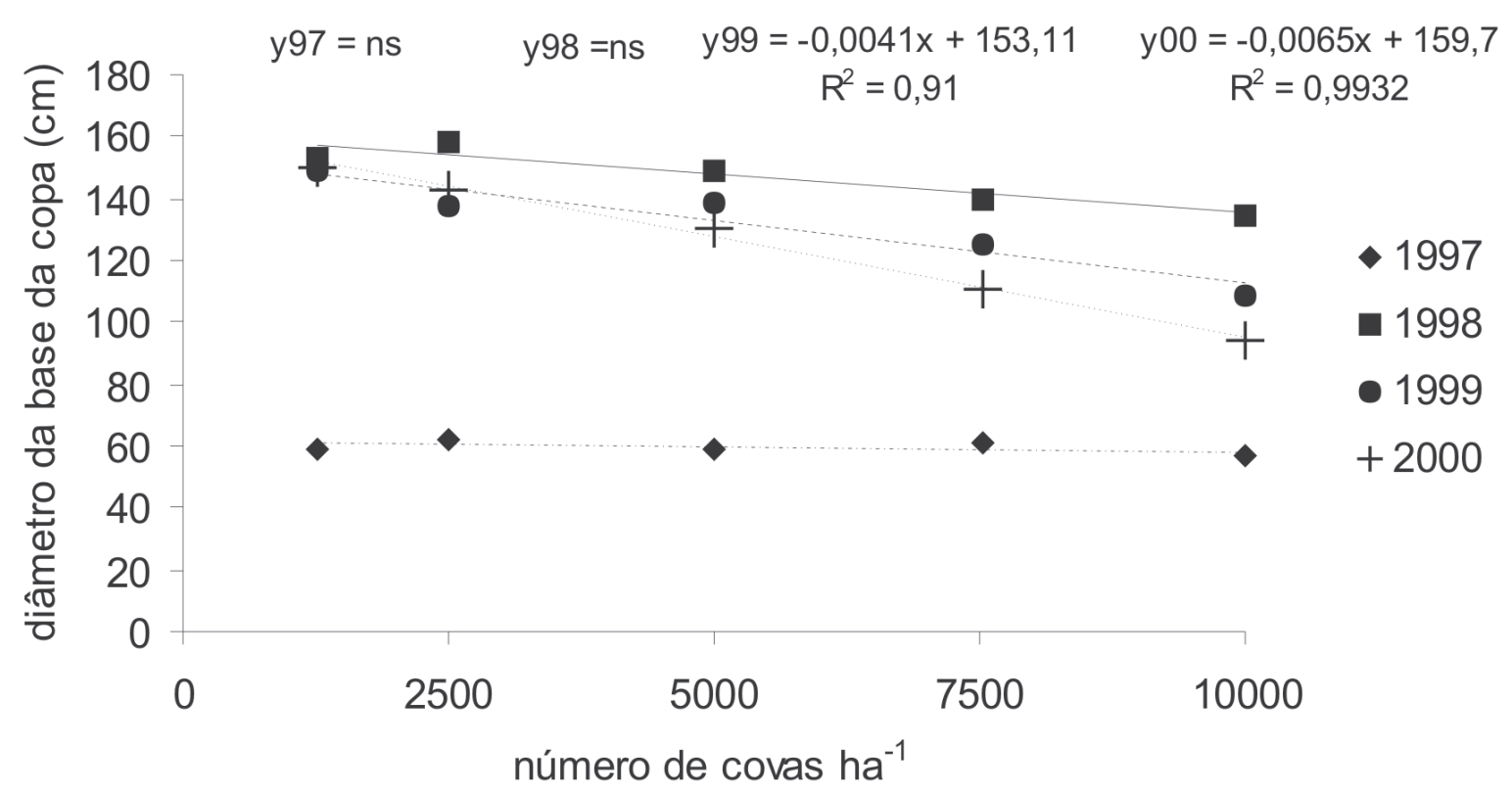

Figura 3. Diâmetro médio da base da copa de cafeeiros de porte baixo submetidos a diferentes densidades de plantio.

Com referência ao número de plantas por cova, a inversão dos resultados talvez possa estar relacionada com a estiagem dos anos 1999 e 2000, havendo efeito protetor e benéfico com o uso de duas plantas por cova. Em cultivares de porte alto já se observou maior diâmetro da base da copa em cafeeiros plantados com duas mudas por cova (SCARANARI e Nogueira, 1963). As diferenças observadas do diâmetro da base da copa dos cafeeiros entre as cultivares e número de plantas por cova, apesar de estatisticamente significativas, aparentemente não têm dimensão que a elas se possa atribuir importância fitotécnica.

A diminuição significativamente linear do diâmetro da copa $(p<0,01)$ para o aumento da população (Figura 3), confirma o relatado para a cultivar Catucaí, cujo diâmetro da base da copa diminuiu com o adensamento da rua (SANTINATO et al., 1994). Contudo, estudo com a cv. Catuaí revelou que essa variável não foi influenciada pelo espaçamento da rua até 4,5 anos de idade, correlacionando-se com o adensamento na fileira e sugerindo que a concorrência das plantas na linha de plantio é o principal fator determinante do crescimento do diâmetro da base da copa (RENA et al., 1996).

\subsection{Altura da planta do solo até a inserção do pri- meiro ramo vivo}

A altura da inserção do primeiro ramo vivo dos cafeeiros não diferiu $(\mathrm{p}>0,05)$ entre as populações e entre as cultivares estudadas, como não foram significativas $(p>0,05)$ a interação entre os fatores população e cultivar e o contraste realizado entre os tratamentos com 2.500 plantas.ha ${ }^{-1}$ para a variável estudada (Tabela 6). Dessa forma, verificam-se nas cultivares Catuaí Amarelo IAC 47 e Obatã IAC 166920 semelhante altura de inserção de seus primeiros ramos, tanto na população de 2.500 plantas ha- ${ }^{-1}$, estabelecida com uma ou duas plantas por cova, quanto na população de 10.000 plantas ha ${ }^{-1}$. A altura média da inserção dos primeiros ramos para essas cultivares foi de $30,08 \mathrm{~cm}$.

O crescimento da haste ortotrópica primária é profundamente modificado pelo espaçamento entre as linhas dos cafeeiros e pela distância dos cafeeiros nas linhas de plantio, sem diferenciar no número de ramos plagiotrópicos, admitindo-se que a altura da planta é determinada principalmente pelo alongamento do entrenó e não pela diferenciação de novos ramos plagiotrópicos, em virtude do adensamento (RENA et al., 1998). Na cultivar Bourbon plantada nas densidades de 10.000 e 13.333 plantas.ha ${ }^{-1}$, respectivamente com três e quatro plantas por cova, perderam ramos até mais ou menos $1,0 \mathrm{~m}$ de altura (GARCiA et al., 1967). No entanto, em estudo com a cv. Catucaí com até 40.000 plantas ha ${ }^{-1}$ não menciona a perda dos ramos da parte de baixo dos cafeeiros (SANTINATO et al., 1994). Os resultados apresentados têm importância para o programa de podas em cafezal adensado, amparando decisões quanto ao tipo de poda a ser efetuada, o que interfere diretamente no ciclo de produção dos cafeeiros. 
Tabela 6. Altura média da inserção dos primeiros ramos dos cafeeiros Catuaí Amarelo IAC 47 e Obatã IAC 1669-20 a partir do nível do solo, submetidos a diferentes densidades de plantio. Os dados são médias de três repetições

\begin{tabular}{ll}
\hline Tratamento & 2000 \\
\hline População (P) & $\mathrm{mm}$ \\
Plantas ha $^{-1}$ & 30,33 \\
$2.500^{(1)}$ & 27,38 \\
$2.500^{(2)}$ & 28,09 \\
5.000 & 29,48 \\
7.519 & 35,13 \\
10.000 & \\
Cultivar (C) & 28,37 \\
Catuaí & 31,79 \\
Obatã & $2,0 \mathrm{~ns}$ \\
\hline F (P) & $1,19 \mathrm{~ns}$ \\
F (1,2) & $4,01 \mathrm{~ns}$ \\
F (C) & $0,63 \mathrm{~ns}$ \\
F (P) x (C) & - \\
F RL & - \\
F RQ & - \\
F 3 ${ }^{\circ} \mathrm{G}$ & - \\
F 4 ${ }^{\circ} \mathrm{G}$ & 17,61 \\
\hline C.V. (P) (\%) & 15,57 \\
C.V. (C) (\%) & \\
\hline
\end{tabular}

( ${ }^{1}$ População de 2.500 plantas.ha ${ }^{-1}$ no espaçamento $4 \times 2 \mathrm{~m}$ com duas plantas por cova.

$\left(^{2}\right)$ População de 2.500 plantas.ha $^{-1}$ no espaçamento $4 \times 1 \mathrm{~m}$ com uma planta por cova.

$\mathrm{F}^{(1,2)}=$ Valor de $\mathrm{F}$ do contraste entre os tratamentos $4 \times 2 \times 2$ e $4 \times 1 \times 1$. $\mathrm{RL}=$ Regressão linear. $\mathrm{RQ}=$ Regressão quadrática. $\mathrm{R} 3 \mathrm{G}=$ Regressão de $3 .^{\circ}$ grau. $\mathrm{R} 4 \mathrm{G}=$ Regressão de $4 .^{\circ}$ grau. ns = não significativo

\subsection{Produtividade}

A produtividade de café beneficiado elevouse significativamente $(p<0,01)$ com o aumento da população, exceto em 2000. As diferenças de produtividade observadas entre as populações de 2.500 plantas $\mathrm{ha}^{-1}$ dispostas com uma e duas plantas por cova não foram significativas $(p>0,05)$ e apenas em 2000 a produtividade da cv. Catuaí Amarelo IAC 47 foi maior que a da Obatã IAC 1669-20 (p<0,01). A interação entre os fatores população e cultivar não foi significativa $(p>0,05)$ em nenhum dos anos do estudo (Tabela 7).

A produtividade média do experimento tendeu a aumentar até 1999, diminuindo drasticamente em 2000 (Figura 4), devido à prolongada estiagem e à deficiência hídrica (Tabela 3), ocorridas em importantes fases do ciclo reprodutivo do cafeeiro, principalmente, florescimento e enchimento de grãos, momento em que a água assume importância relevante na cultura do café.

$\mathrm{O}$ aumento da produtividade com o tempo era esperado, uma vez que o cafeeiro é uma planta de crescimento contínuo ou indefinido. $\mathrm{Na}$ cv. Catuaí Vermelho têm sido verificados aumentos da produtividade com a população (VALENCIA, 1973; URIBE e Mestre, 1988A,B; Pavan et al., 1994) e com o tempo (PAVAn et al., 1994), podendo mostrar acentuado ciclo bienal da produção, o que não se observou nesse trabalho.

As diferenças observadas entre as produtividades dos tratamentos com 2.500 plantas por hectare, embora maior em todas as colheitas com a população estabelecida com uma e não com duas plantas por cova, foram não significativas $(\mathrm{P}>0,05)$, concordando com o relatado para a cv. Catuaí Vermelho (SiqueIRA et al., 1983).

Observou-se que a produtividade aumentou linearmente com a densidade de plantio nas duas primeiras colheitas, mas não em 1999, quando a produtividade da população de 10.000 plantas foi inferior à de 7.519 plantas.ha $^{-1}$ (Tabela 7), de comportamento quadrático (Figura 3). O resultado leva a entender que até a colheita de 1998 a competição entre os cafeeiros pelos recursos do meio não alcançou magnitude que reduzisse a produtividade das diferentes populações, ocorrendo em 1999 o pico de produção para a população de 10.000 plantas ha ${ }^{-1}$. Merece importância a observação, pois cafeeiros de porte baixo e em menores densidades de plantio obtêm picos de produção mais tardios que os cafeeiros de porte alto e maiores populações. O pico da produção indica o efeito da população e a necessidade de uso de podas para o retorno do ciclo de produção (PAVAn et al., 1994).

\subsection{Produção de café por planta}

A produção de café beneficiado por planta diminuiu significativamente $(p<0,01)$ com o aumento da densidade de plantio dos cafeeiros, excetuandose o primeiro ano da colheita. A análise de regressão foi significativa em níveis de $1 .^{\circ}(p<0,01)$ e $2 .^{\circ}(p<0,05)$ graus em 1998, 1999 e para o total de café beneficiado por planta no quadriênio e em níveis de $1 .^{\circ}(\mathrm{p}<0,01)$ e $3 .^{\circ}(\mathrm{p}<0,05)$ graus em 2000. 
Tabela 7. Produtividade média de café beneficiado dos cafeeiros Catuaí Amarelo IAC 47 e Obatã IAC 1669-20 submetidas a diferentes densidades de plantio. Os dados são médias de três repetições

\begin{tabular}{|c|c|c|c|c|c|c|}
\hline Tratamento & 1997 & 1998 & 1999 & 2000 & Total & Média \\
\hline População (P) Plantas ha-1 & 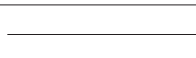 & 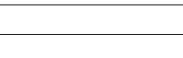 & $\mathrm{kg} \cdot \mathrm{ha}^{-1}$ & & 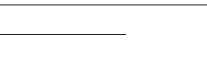 & \\
\hline $2.500^{(1)}$ & 827,0 & $1.266,5$ & $1.711,7$ & 510,2 & $4.315,4$ & $1.078,9$ \\
\hline $2.500^{(2)}$ & $1.325,7$ & $1.249,1$ & $2.336,0$ & 599,0 & $5.509,8$ & $1.377,5$ \\
\hline 5.000 & $2.571,9$ & $2.692,8$ & $4.713,9$ & 553,1 & $10.351,8$ & $2.588,0$ \\
\hline 7.519 & $3.225,5$ & $2.683,0$ & $5.535,1$ & 279,6 & $11.723,2$ & $2.930,8$ \\
\hline 10.000 & $4.285,6$ & $3.067,2$ & $4.326,6$ & 335,2 & $12.314,6$ & $3.078,7$ \\
\hline \multicolumn{7}{|l|}{ Cultivar (C) } \\
\hline Catuaí & $2.491,0$ & $2.119,0$ & $3.674,8$ & 577,2 & $8.862,0$ & $2.216,0$ \\
\hline Obatã & $2.403,3$ & $2.264,4$ & $3.894,5$ & 333,7 & $8.895,9$ & $2.224,0$ \\
\hline $\mathrm{F}(\mathrm{P})$ & $26,70 * *$ & $28,45 * *$ & $15,74 * *$ & $1,82 \mathrm{~ns}$ & $30,29 * *$ & - \\
\hline$F(1,2)$ & $1,24 \mathrm{~ns}$ & $0,01 \mathrm{~ns}$ & $1,01 \mathrm{~ns}$ & $0,74 \mathrm{~ns}$ & $1,18 \mathrm{~ns}$ & - \\
\hline$F(C)$ & $0,10 \mathrm{~ns}$ & $0,98 \mathrm{~ns}$ & $0,31 \mathrm{~ns}$ & $13,92 * *$ & $0,00 \mathrm{~ns}$ & - \\
\hline$F(P) \times(C)$ & $0,21 \mathrm{~ns}$ & $3,23 \mathrm{~ns}$ & $2,08 \mathrm{~ns}$ & $1,42 \mathrm{~ns}$ & $0,39 \mathrm{~ns}$ & - \\
\hline F RL & $105,31 * *$ & $96,08 * *$ & $46,51^{* *}$ & - & $109,06^{* *}$ & - \\
\hline F RQ & $0,27 \mathrm{~ns}$ & $1,15 \mathrm{~ns}$ & $8,71 *$ & - & $4,01 \mathrm{~ns}$ & - \\
\hline $\mathrm{F} 3^{\circ} \mathrm{G}$ & $0,16 \mathrm{~ns}$ & $4,32 \mathrm{~ns}$ & $6,92 *$ & - & $4,33 \mathrm{~ns}$ & - \\
\hline $\mathrm{F} 4^{\circ} \mathrm{G}$ & $1,06 \mathrm{~ns}$ & $12,28 * *$ & $0,80 \mathrm{~ns}$ & - & $3,74 \mathrm{~ns}$ & - \\
\hline C.V. (P) (\%) & 27,20 & 18,16 & 27,09 & 55,78 & 18,56 & - \\
\hline C.V.(C) $(\%)$ & 31,73 & 18,38 & 28,36 & 39,25 & 21,45 & - \\
\hline
\end{tabular}

( $\left.{ }^{1}\right)$ População de 2.500 plantas.ha ${ }^{-1}$ no espaçamento $4 \times 2 \mathrm{~m}$ com duas plantas por cova.

${ }^{2}$ População de 2.500 plantas.ha ${ }^{-1}$ no espaçamento $4 \times 1 \mathrm{~m}$ com uma planta por cova.

$\mathrm{F}^{(1,2)}$ Valor de $\mathrm{F}$ do contraste entre os tratamentos $4 \times 2 \times 2$ e $4 \times 1 \times 1$.

$\mathrm{RL}=$ Regressão linear. $\mathrm{RQ}=$ Regressão quadrática. $\mathrm{R} 3 \mathrm{G}=$ Regressão de $3 .^{\circ}$ grau. $\mathrm{R} 4 \mathrm{G}=$ Regressão de $4 .^{\circ}$ grau.

ns = não significativo.

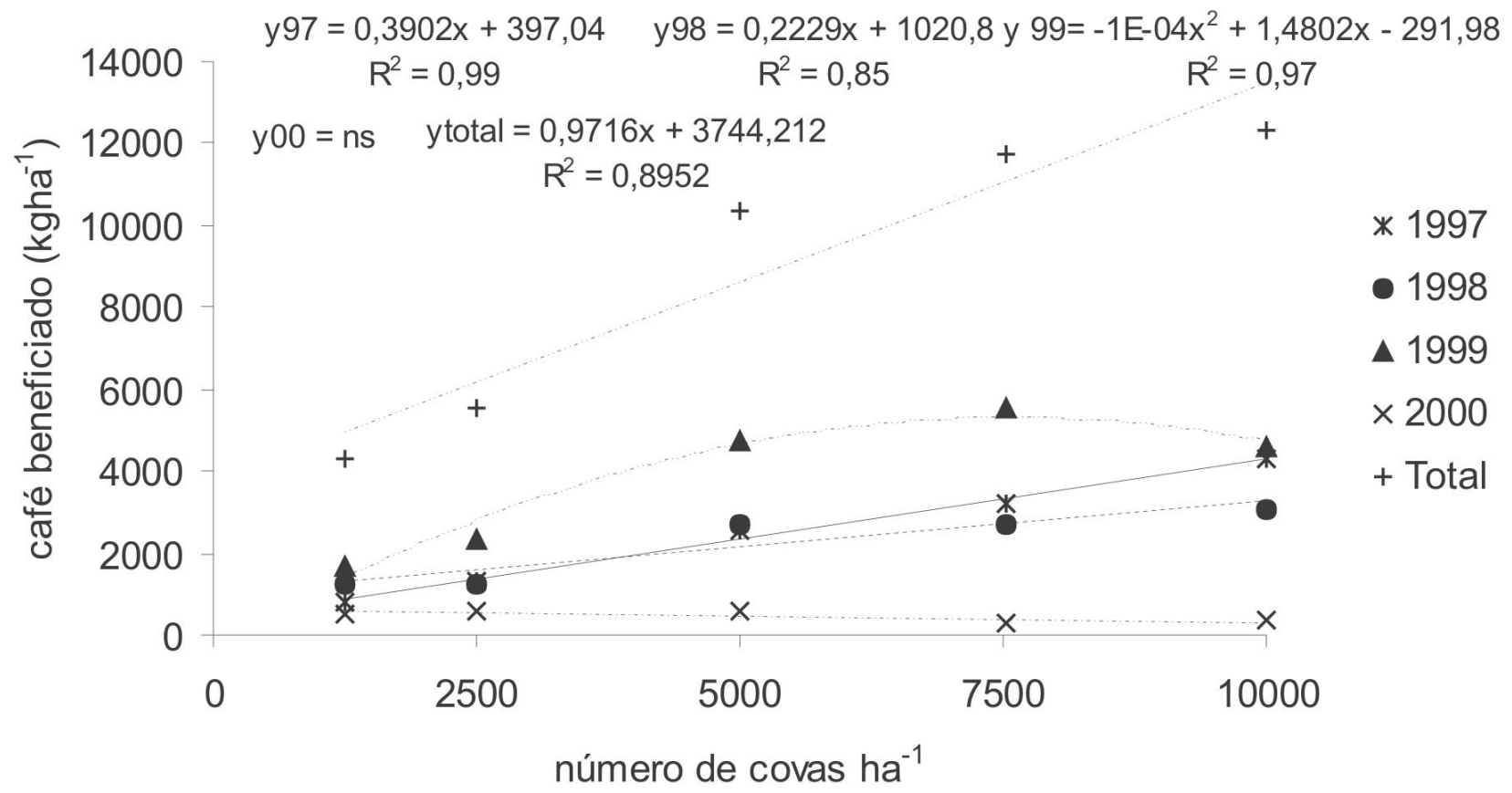

Figura 4. Produtividade de cafeeiros de porte baixo submetidos a diferentes densidades de plantio. 
O contraste entre as produções de café beneficiado por planta nas populações de 2.500 plantas por hectare, estabelecidas com uma e duas plantas por cova, não foi significativo $(p>0,05)$ em 1998 e 1999, obtendo-se nos outros anos e no total do quadriênio as maiores produções para a disposição da população com uma planta por cova. Somente em 2000 observou-se diferença na produção por planta entre as cultivares, quando a cv. Catuaí Amarelo IAC 47 produziu significativamente $(p<0,01)$ mais café beneficiado por planta que a cv. Obatã IAC 1669-20. Nesse ano, a interação entre os fatores população e cultivar foi significativa $(p<0,05)$ (Tabela 8). O estudo da regressão da população dentro das cultivares revelou que a população não influenciou a produção de café na cultivar Obatã IAC 1669-20 ( $p>0,05)$, mas sim na Catuaí Amarelo IAC 47 em níveis de $1 .^{\circ}$ $(p<0,01)$ e $2 .^{\circ}(p<0,5)$.

A resposta em produção de café beneficiado por planta das cultivares ao aumento da população de cafeeiros por área está representada na Figura 4.
A diminuição da produção de café beneficiado por planta com o aumento da densidade populacional proporcionado pelas cultivares (Tabela 8; Figura 5) pode ser explicada pelo concomitante aumento da competição intraespecífica por água, luz e nutrientes.

No que se refere à competição por água, verifica-se que com o crescimento das plantas e o aumento da densidade de plantio, deve haver aumento no consumo de água por unidade de área, resultando menores colheitas (KIARA e StOlZI, 1985). Contudo, tem-se afirmado que a água não é fator restritivo para a adoção de sistemas de plantio adensados (GATHAARA e KiARA, 1984) e que o aumento da população não implica maior consumo de água (LiBRAN et al., 1985). É necessário mencionar que o aumento da densidade populacional diminui a transpiração (FISHER e BROWNING, 1978, LiBRAN et al., 1985) e pode não proporcionar diminuição do potencial hídrico nas plantas (FISHER e BROWNING, 1978, 1979, GathaAra e Kiara, 1984).

Tabela 8. Produção média de café beneficiado por planta dos cafeeiros Catuaí Amarelo IAC 47 e Obatã IAC 1669-20 submetidas a diferentes densidades de plantio. Os dados são médias de três repetições

\begin{tabular}{|c|c|c|c|c|c|}
\hline Tratamento & 1997 & 1998 & 1999 & 2000 & Total \\
\hline População (P) & \multicolumn{5}{|c|}{ g.planta ${ }^{-1}$} \\
\hline \multicolumn{6}{|l|}{ Plantas.ha ${ }^{-1}$} \\
\hline $2.500^{(1)}$ & 330,8 & 506,6 & 684,7 & 204,1 & $1.726,2$ \\
\hline $2.500^{(2)}$ & 530,3 & 499,7 & 934,4 & 239,6 & $2.203,9$ \\
\hline 5.000 & 514,4 & 538,6 & 942,8 & 110,6 & $2.106,4$ \\
\hline 7.519 & 429,0 & 356,8 & 736,2 & 37,2 & $1.559,2$ \\
\hline 10.000 & 428,6 & 306,7 & 462,7 & 33,5 & $1.231,5$ \\
\hline \multicolumn{6}{|l|}{ Cultivar (C) } \\
\hline Catuaí & 469,1 & 439,9 & 750,7 & 162,4 & $1.812,1$ \\
\hline Obatã & 424,1 & 453,5 & 753,5 & 87,6 & $1.718,7$ \\
\hline $\mathrm{F}(\mathrm{P})$ & $1,46 \mathrm{~ns}$ & 4,53 * & $4,38 *$ & $7,42 * *$ & $6,55 *$ \\
\hline $\mathrm{F}(1,2)$ & $6,51 *$ & $0,02 \mathrm{~ns}$ & $6,87^{* *}$ & $2,89 \mathrm{~ns}$ & $6,45 *$ \\
\hline $\mathrm{F}(\mathrm{C})$ & $0,83 \mathrm{~ns}$ & $0,59 \mathrm{~ns}$ & $0,00 \mathrm{~ns}$ & $31,98 * *$ & $0,62 \mathrm{~ns}$ \\
\hline$F(P) \times(C)$ & $0,66 \mathrm{~ns}$ & $2,25 \mathrm{~ns}$ & $1,46 \mathrm{~ns}$ & $6,30 * *$ & $0,89 \mathrm{~ns}$ \\
\hline F RL & - & $12,59 * *$ & $4,57 \mathrm{~ns}$ & $24,60 * *$ & $10,97 *$ \\
\hline F RQ & - & $2,88 \mathrm{~ns}$ & $12,59 * *$ & $0,03 \mathrm{~ns}$ & $12,46^{* *}$ \\
\hline $\mathrm{F} 3 .^{\circ} \mathrm{G}$ & - & $0,31 \mathrm{~ns}$ & $0,34 \mathrm{~ns}$ & $4,57 \mathrm{~ns}$ & $2,60 \mathrm{~ns}$ \\
\hline $\mathrm{F} 4 .^{\circ} \mathrm{G}$ & - & $2,34 \mathrm{~ns}$ & $0,02 \mathrm{~ns}$ & $0,50 \mathrm{~ns}$ & $0,17 \mathrm{~ns}$ \\
\hline CV (P) (\%) & 36,33 & 26,82 & 30,94 & 67,93 & 21,65 \\
\hline CV $(\mathrm{C})(\%)$ & 30,33 & 19,03 & 21,94 & 28,96 & 18,46 \\
\hline
\end{tabular}

( $\left.{ }^{1}\right)$ População de 2500 plantas.ha ${ }^{-1}$ no espaçamento $4 \times 2 \mathrm{~m}$ com duas plantas por cova.

(2) População de 2500 plantas.ha- ${ }^{-1}$ no espaçamento $4 \times 1 \mathrm{~m}$ com uma planta por cova.

$\mathrm{F}^{(1,2)}=$ Valor de $\mathrm{F}$ do contraste entre os tratamentos $4 \times 2 \times 2$ e $4 \times 1 \times 1$.

$\mathrm{RL}=$ Regressão linear. $\mathrm{RQ}=$ Regressão quadrática. $\mathrm{R} 3 \mathrm{G}=$ Regressão de $3 .^{\circ}$ grau. $\mathrm{R} 4 \mathrm{G}=$ Regressão de $4 .^{\circ}$ grau.

ns = não significativo 


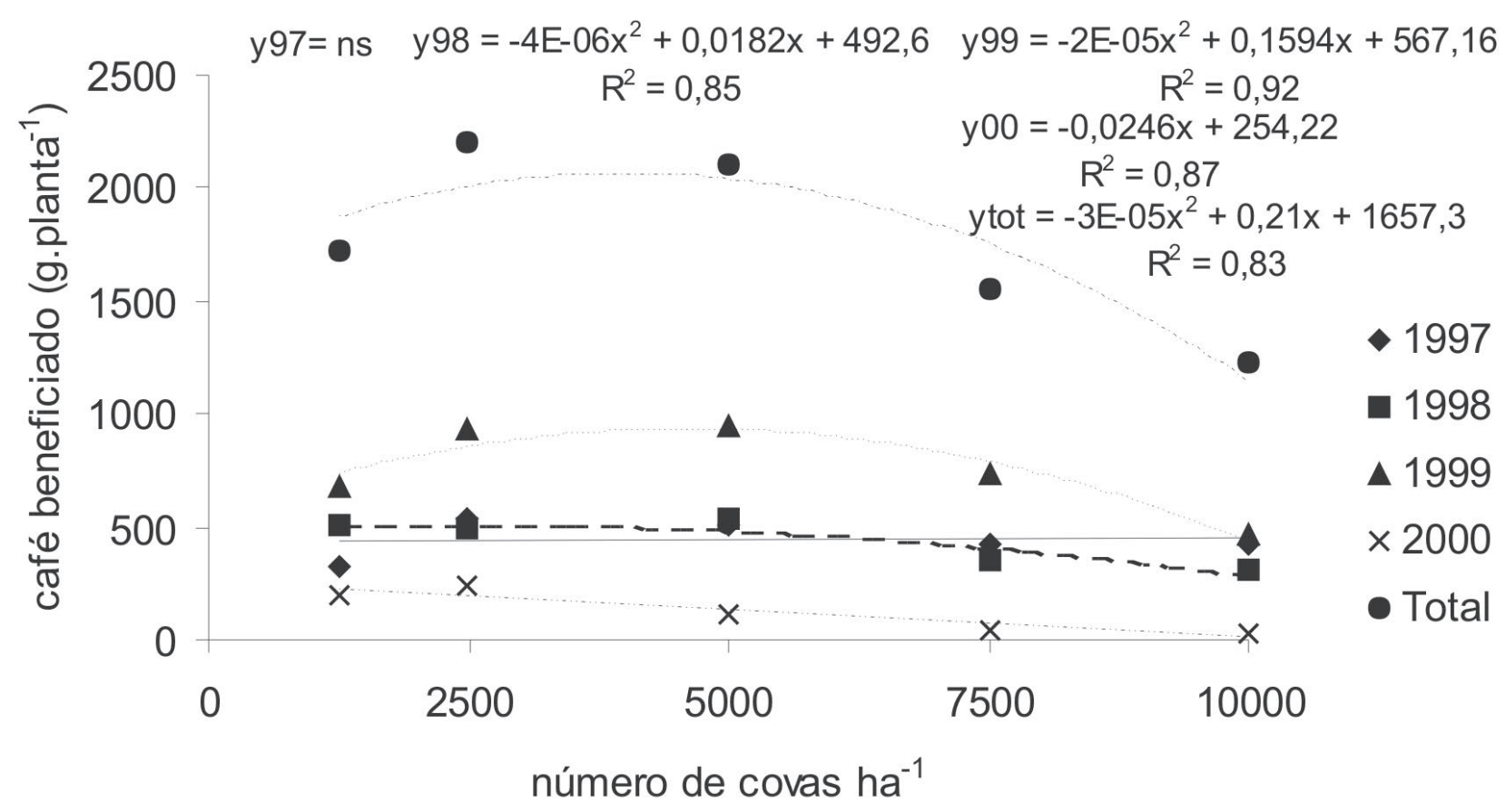

Figura 5. Produção de cafeeiros de porte baixo submetidos a diferentes densidades de plantio.

Contudo, com o crescimento das plantas, observou-se de modo geral nas várias populações aumento da produção individual dos cafeeiros até 1999, mas não claramente naquela com 10.000 plantas $\mathrm{ha}^{-1}$ (Tabela 8). As menores produções individuais em 2000 são decorrentes da severa deficiência hídrica (Tabela 3) a que foram submetidos os cafeeiros quando a produção por planta diminuiu linearmente com o aumento da população de plantas (Tabela 8). Os resultados obtidos levam a considerar que a disponibilidade hídrica pode ser um fator relevante na definição das densidades de plantio para cafeeiros de porte baixo.

\section{CONCLUSÕES}

1. As cultivares Catuaí Amarelo IAC 47 e Obatã IAC 1669-20 não diferem entre si quanto à produção individual e à produtividade de café beneficiado no primeiro quadriênio.

2. O aumento da densidade de plantio influencia positivamente a altura e negativamente o diâmetro do caule e da base da copa de cafeeiros, mas não a altura do primeiro ramo plagiotrópico da planta a partir do nível do solo.

3. O aumento da população de cafeeiros acarreta menor produção de café beneficiado por planta, mas aumenta a produtividade.

\section{REFERÊNCIAS}

ALMEIDA, S.R.; MATIELLO, J.B. Comparação de sistemas de plantio com mudas simples e duplas, com diferentes números de mudas por cova. In: CONGRESSO BRASILEIRO DE PESQUISAS CAFEEIRAS, 8., 1980, Campos de Jordão. Resumos... Rio de Janeiro: IBC-GERCA, 1980. p. 52-61.

ANDROCIOLI FILHO, A. Procedimentos para o adensamento de plantio e contribuição para o aumento da produtividade. In: CARAMORI, P.H, ANDROCIOLI FILHO, A., LIBERAL, E. G., CHAVES, J.C.D., CARNEIRO, R.G. (Ed.). SIMPÓSIO INTERNACIONAL SOBRE CAFÉ ADENSADO, 1994, Londrina. Anais... Londrina: IAPAR, 1996. p. 251-275

CAMARGO, A.P.; ALMEIDA, S.R.; MIGUEL, A.E.; MATIELLO, J.B. Ensaio de espaçamentos progressivos em Varginha - MG. Resultados das sete primeiras colheitas. In: CONGRESSO BRASILEIRO DE PESQUISAS CAFEEIRAS, 12., 1985, Caxambu. Trabalhos apresentados... Rio de Janeiro: IBC-GERCA, 1985. p. 36-37.

CAVICHIOLI, J.C. Efeitos de iluminação artificial sobre o cultivo do maracujazeiro amarelo (Passiflora eduli Sims f. flavicarpa Deg). 1998. 124p. Dissertação (Mestrado) - Universidade Estadual Paulista, Faculdade de Ciências Agrárias e Veterinárias, Jaboticabal.

FAZUOLI, L.C. Contribuição da pesquisa para obtenção de cafeeiros adaptados ao plantio adensado. In: CARAMORI, P.H (Ed.) (Org.). SIMPÓSIO INTERNACIONAL SOBRE CAFÉ ADENSADO, 1994. Londrina. Anais... Londrina: IAPAR, 1996. p. 1-43. 
FAZUOLI, L.C.; MEDINA FILHO, H.P.; GONÇALVEZ, W.; GUERREIRO FILHO, O.; SILVAROLLA, M.B. Melhoramento do cafeeiro: variedades tipo arabica obtidas no Instituto Agronômico de Campinas. In: ZAMBOLIN, L. (Org.). O estado de arte de tecnologias na produção de café. Viçosa - MG, 2002, p. 163-215.

FISHER, N.M.; BROWNING, G. Some effects of irrigation and plant density on the water relations of high density coffee (Coffea arabica L.). Kenya Journal of Horticultural Science, Nairobi, v. 54, n. 1., p. 13-22, 1979.

FISHER, N.M.; BROWNING, G. The water requirement of high density coffee: I. Responses to irrigation and plant water stress measurements. Kenya Coffee, Nairobi, v .43, n503, p.43-46, 1978.

GARCIA, A.N.; RIVAS, V.; BELLAVITA, O. Comparación de varias densidades de siembra en cafetales. Agronomia Tropical, Maracay, v. 17, n. 3, p. 187-193, 1967.

GATHAARA, M.P.H.; KIARA, J.M. Factors that influence yield in close-spaced coffee.1. Light, dry matter production and plant water status. Kenya Coffee, Nairobi, v. 49, n. 580 p.203-211, 1984.

GOMES, F.P. Curso de Estatística Experimental. 8.ed. Piracicaba: Nobel, 1978. 430 p.

KIARA, J.M.; STOLZI, L.H. The effects of tree density and irrigation on coffee growth and production in Kenya. Applied Agricultural Research, New York, v. 1, p.26-31, 1985.

LIBRAN, L.; MORALES, D.; CORTES, S. Estudio preliminar sobre la intensidad transpiratoria del cafeto cultivado a diferentes densidades de plantación. Cultivos Tropicales, Havana, v.7, n.2, p. 109-11, 1985.

MELLO, M.H.A.; PEDRO JUNIOR., M.J.; LOMBARDI NETO, F. Potencialidades agrícolas das terras do Estado de São Paulo. In: LOMBARDI NETO, F.; DRUGOWICH M.I. (Coord.). Manual técnico de manejo e conservação do solo. Campinas: CATI, 1994. v.1. p.1-69. (Manual, 39)

NJOROGE, J.M.; WAITHAKA, K., CHWEYA, J.A. The influence the tree training and plant density on growth, yields components and yield of arabica coffee cv. Ruiru 11. Journal of Horticultural Science, Cambridge, v. 67, n. 5, p. 695-702, 1992.

PAVAN, M.A.; CHAVES, J.C.D.; ANDROCIOLI FILHO, A. Produção de café em função da densidade de plantio, adubação e tratamento fitossanitário. Turrialba, San Jose, v.44, n.4, p.227231, 1994.

PRADO, H.; TREMOCOLDI, W.A.; MENK, J.R.F. Levantamento pedológico detalhado do Pólo Regional de Desenvolvimento Tecnológico dos Agronegócios da Alta Paulista, Adamantina (SP). Campinas: Instituto Agronômico, 2003. 27p. (Série Pesquisa APTA. Boletim Científico, 10)

RAIJ, B. VAN; FERNANDES, R.D.; OLIVEIRA, E.G.; MALAVOLTA, E.; CERVELLINI, G.S.; CANTARELLA, H.; BARROS, I.; TOLEDO FILHO, J.A.; PEREIRA, L.C.E.; GALLO, P.B.; THOMAZIELLO, R.A.; BONINI, R.; COSTA, T.E. Café.. In: RAIJ, B. VAN, CANTARELLA, J.A, QUAGGIO, J.A, FURLANI, A.M.C. (Ed.) Recomendações de adubação e calagem para o Estado de São Paulo. Campinas: Instituto Agronômico/Fundação IAC, 1997. p. 97-101. (Boletim Técnico, 100)
RENA, A.B.; MAESTRI, M. Ecofisiologia do cafeeiro. In: CASTRO, R.C., FERREIRA, S.O., YAMADA, T. (Ed.). Ecofisiologia da produção agrícola. Piracicaba: Associação Brasileira para Pesquisa da Potassa e do Fosfato, 1987. p. 119-147.

RENA, A.B.; MAESTRI, M. Fisiologia do cafeeiro. In: RENA, A.B.; MALAVOLTA, E.; ROCHA, E.; YAMADA, T. (Ed.). Cultura do cafeeiro: Fatores que afetam a produtividade. Piracicaba: Associação Brasileira para Pesquisa da Potassa e do Fosfato, 1986. p. 13-85.

RENA, A.B., NACIF, A.P., GONTIJO, P.T.G., PEREIRA, A.A. Fisiologia do cafeeiro em plantios adensados. In: CARAMORI, P.H, ANDROCIOLI FILHO, A., LIBERAL, E. G., CHAVES, J.C.D., CARNEIRO, R.G. (Ed.). SIMPÓSIO INTERNACIONAL SOBRE CAFÉ ADENSADO, 1994, Londrina. Anais... Londrina: IAPAR, 1996. p.72-85.

RENA, A.B., NACIF, A.P., GUIMARÃES, P.T.G., BARTHOLO, F.G. Plantios adensados de café: Aspectos morfológicos, ecofisilógicos, fenológicos e agronômicos. Informe Agropecuário, Belo Horizonte, v.19, n.193, p.61-70, 1998.

SANTINATO, R., MATIELLO, J.B., SILVA, W.J., CARVALHO, R. Espaçamentos (hiper, super e adensado) na rua e na linha de plantio para cafeeiros resistentes à ferrugem, variedades Icatu 2944, Catucai e Mundindu. In: CONGRESSO BRASILEIRO DE PESQUISAS CAFEEIRAS, 20., 1994, Guarapari. Resumos... Rio de Janeiro: MAARA/PROCAFÉ, 1994. p. 176-180.

SCARANARI, H.J., NOGUEIRA NETO, P. Efeito da densidade de plantio sobre a produção de café. Mundo Novo. Bragantia, Campinas, v. 22, n. 29, p.373-382, 1963.

SIQUEIRA, R., ANDROCIOLI FILHO, A., PAVAN, M.A., CHAVES, J.C.D. Densidade de plantio, poda dos primeiros ramos e produção de duas cultivares de café e do híbrido Icatu. Pesquisa Agropecuária Brasileira, Brasília, v. 18, n. 2, 763-69, 1983.

URIBE, H.A., MESTRE, M. A. Efeito de la densidad de la poblacion y su sistema de manejo sobre la produccion de café. Cenicafe, Chinchina, v.31, p.29-51, 1980.

URIBE, H.A., MESTRE, M.A. Efecto de la distancia de siembra y del numero de plantas por hoyo sobre la producción de café (Coffea arabica L.) var. Caturra. Cenicafe, Chinchina, v. 39, n. 1, p. 15-27, 1988a.

URIBE, H.A., MESTRE, M.A. Efecto de la densidad de poblacion y de la disposicion de los arboles em la producion de café. Cenicafe, Chinchina, v.39, n.2, p.31-42, 1988b.

VALÊNCIA, A.G. Relação entre o índice de área foliar e a produtividade do café. Cenicafé, Chinchina, v.23, p. 79-89, $1973 b$. 